\title{
Trial of Labour after Caesarean Section: A 5-Year Review
}

\author{
Francis Olayemi Adebayo*, Rafat Bolanle Muhammad, Nathaniel Adewole, \\ Adedeji Oyeniyi Adesope \\ Department of Obstetrics and Gynaecology, University of Abuja Teaching Hospital, Abuja-FCT, Nigeria \\ Email: *preciousdavis67@yahoo.com
}

How to cite this paper: Adebayo, F.O. Muhammad, R.B., Adewole, N. and Adesope, A.O. (2018) Trial of Labour after Caesarean Section: A 5-Year Review. Open Journal of Obstetrics and Gynecology, 8, 1121-1129.

https://doi.org/10.4236/ojog.2018.812113

Received: August 27, 2018

Accepted: October 5, 2018

Published: October 8, 2018

Copyright $(9) 2018$ by authors and Scientific Research Publishing Inc. This work is licensed under the Creative Commons Attribution International License (CC BY 4.0).

http://creativecommons.org/licenses/by/4.0/

\begin{abstract}
Background: Trial of labour after Caesarean section (TOLAC) refers to an attempt at vaginal delivery after a previous caesarean section. Outcome is influenced by a number of factors which are important in patient's selection. Objectives: The aim of this study was to find out the incidence and feto-maternal outcome of the practice of Trial of labour after Caesarean section. Methodology: This is a retrospective study of cases of vaginal birth after Caesarean section Data were retrieved from the case notes of patients who attempted vaginal birth after Caesarean section from January 1, 2013 to December 31, 2017, a period of five years. Result: There were 10,669 deliveries, 3179 of which were through Caesarean section. This gave a Caesarean section rate of $29.8 \%$. A total of 217 patients attempted vaginal birth after Caesarean section and 83 ended up as repeat Caesarean section (38.2\%) while 138 (61.8\%) had successful vaginal birth after Caesarean section. Patients with previous vaginal delivery, age range $25-29$ years and interdelivery interval of greater than or equal to 2 years were more successful at achieving vaginal birth after Caesarean section. The leading indications for the repeat Caesarean section include cephalopelvic disproportion (45.8\%), poor progress of labour (19.3\%) and hypertensive disorders of pregnancy (8.4\%). Conclusion: Vaginal birth after Caesarean section was successful in most of the parturients that attempted it in this study especially in patients within the age range of $25-29$ years, those that have had previous vaginal delivery and with interdelivery interval of greater than or equal to 2 years.
\end{abstract}

\section{Keywords}

Trial of Labour after Caesarean Section, Vaginal Birth after Caesarean Section, Inter-Delivery Interval 


\section{Introduction}

Labour after a previous Caesarean section is otherwise known as Vaginal Birth after Caesarean, VBAC [1]. For a woman with a previous Caesarean delivery, assuming no mitigating circumstances, there are two basic choices. First is a Trial of Labour after Caesarean (TOLAC) with a goal of achieving Vaginal Birth after Caesarean, VBAC [2]. If Caesarean delivery becomes necessary during the trial, then it is called a "failed trial of labour" [2]. The second choice is elective repeat Caesarean delivery [2]. This includes scheduled Caesarean delivery as well as unscheduled but planned Caesarean delivery for spontaneous labour or another indication [2].

The prevalence of vaginal birth after Caesarean section has varied over the last 100 years depending on the period being considered. This was because of the controversies that have surrounded the concept of vaginal birth after Caesarean section over the past 100 years as evidenced by Craigin's famous dictum, "Once a Caesarean, always a Caesarean" and also that by Flamm, "Once a Caesarean, always a controversy" [3] [4]. These controversies have served to either increase the incidence of vaginal birth after Caesarean section or decrease it depending on the direction of swing of pendulum of opinion [5]. Hence, in the United State, the rate of vaginal birth after Caesarean section increased from $3.4 \%$ in 1980 to a peak of $28.3 \%$ in 1996 [6]. However, as the rate of vaginal birth after Caesarean section increased, so did reports of uterine rupture-related maternal and perinatal morbidity and mortality so much that by 2011, the rate of vaginal birth after Caesarean section had dropped to about 8\% [6] [7].

The rate of successful vaginal birth after Caesarean section in most African countries is between $60 \%$ and $80 \%$ [8]. At the University of Benin Teaching Hospital, the rate is 66\% [8]. At Nnamdi Azikiwe University Teaching Hospital, the rate was $46.7 \%$ [9]. In Lagos, the rate was $73 \%$ while in another study from Benin it was $48 \%$ [10] [11].

The predictive factors of a successful vaginal birth after Caesarean section include previous vaginal birth, non recurrent indication for the previous Caesarean section and 18 months interdelivery interval [12] [13] [14]. Other positive predictive factors include foetal weight of less than $4 \mathrm{~kg}$ and singleton pregnancy [15] [16]. Negative predictive factors of success of vaginal birth after Caesarean section include pregnancy and delivery within 12 months of the previous Caesarean section, birth weight greater than $4 \mathrm{~kg}$ and obesity [15] [17] [18].

Some of the benefits of vaginal birth after Caesarean section are less hospital stay, reduced cost, earlier mother to child bonding and avoidance of the anaesthetic and other complications associated with Caesarean delivery [16] [19]. There is also less blood loss in successful vaginal birth after Caesarean section [20].

With attempt at vaginal birth after Caesarean section, even though the overall risks of uterine rupture and its associated complications as well as the risk of intrapartum and neonatal deaths are small, what is not in doubt is the fact that 
these are higher compared to repeat Caesarean delivery [2]. This was well highlighted by the National Institutes of Health Consensus Development Conference Panel (in the US) which concluded that in a hypothetical group of 100,000 women of any gestational age who undergo TOLAC, there will be 4 maternal deaths, 468 cases of uterine rupture, and 133 perinatal deaths. In comparison, in a hypothetical group of 100,000 women of any gestational age who undergo Elective Repeat Caesarean Delivery, there will be 13 maternal deaths, 26 uterine ruptures, and 50 perinatal deaths [2]. Hence, recommendations such as availability of continuous electronic monitoring, blood bank backup, monitoring by a physician capable of performing emergency CS and availability of an anaesthetist should be met [8] [19]. A previous classical Caesarean section is an absolute contraindication to attempting vaginal birth after Caesarean section [2].

There is no previous study on Vaginal Birth after Caesarean section in this centre. As demonstrated above, regular review of the practice of Vaginal Birth after Caesarean section is necessary to make an optimal decision with respect to the management of the patient with previous Caesarean section. This study was carried out to determine the incidence, predictive factors and the outcome of the practice of trial of labour after Caesarean at the University of Abuja Teaching Hospital, Abuja.

\section{Materials and Method}

This was a 5 year retrospective review of cases of Trial of Vaginal Birth after Caesarean that took place between $1^{\text {st }}$ of January, 2013 to the $31^{\text {st }}$ of December, 2017. It was only 217 out of the 221 case notes that were available for review as 4 of the 221 case notes in the group that had successful vaginal birth after Caesarean section could not be found.

The hospital numbers of patients who attempted Vaginal Birth after Caesarean section within the years of review were collected from the Labour Ward register and Obstetric theatre register and the case notes were retrieved from the Medical Records Department. The information extracted from the case notes included; age, parity, booking status, previous vaginal delivery, inter-delivery interval, the indication for both previous Caesarean section and termination of TOLAC as well as fetomaternal outcome of the attempt at vaginal birth after caesarean section and duration of hospital stay. Relevant data listed above were retrieved, documented and analysedusing Statistical Package for Social science (SPSS) version 20. Statistical analysis was by simple percentage.

\section{Result}

A total of ten thousand six hundred and sixty-nine women $(10,669)$ delivered in this facility within the period under review, 3179 of whom had Caesarean section. This gave a Caesarean section rate of $29.8 \%$. Two hundred and twenty one (217) patients attempted vaginal birth after Caesarean section. One hundred and thirty four $(61.8 \%)$ of the patients had successful vaginal birth after Caesarean 
section while eighty three (38.2\%) failed to achieve vaginal birth after Caesarean section and therefore had emergency repeat Caesarean section.

The age range of the patients was 20 - 44 years. One hundred and sixty $(73.7 \%)$ of the women were booked while fifty seven $(26.3 \%)$ were unbooked. Patients with previous vaginal delivery, age between 25 - 29 years and interdelivery interval of greater than or equal to 2 years were more successful at achieving vaginal birth after Caesarean section than those outside these categories (See Table 1).

As listed in Table 2, Malpresentation is the major indication for the previous Caesarean section prior to the attempts at vaginal birth after Caesarean section while obstructed labour and poor progress were the least. Eleven patients had their labour augmented. Five of them had successful vaginal birth after Caesarean section while 6 had failed attempts at VBAC. The commonest indications for the termination of the attempts at vaginal birth after Caesarean section were

Table 1. Socio-demographic Characteristics.

(a)

\begin{tabular}{ccccc}
\hline S/N & AGE GROUP & VBAC (\%) & FAILED VBAC & TOTAL \\
\hline 1 & $20-24$ & $26(19.4)$ & $18(21.7)$ & 44 \\
2 & $25-29$ & $48(35.8)$ & $25(30.1)$ & 73 \\
3 & $30-34$ & $47(35.1)$ & $33(39.8)$ & 80 \\
4 & $35-39$ & $13(9.7)$ & $5(6.0)$ & 18 \\
5 & $40-44$ & 0 & $2(2.4)$ & 2 \\
S/N & & 134 & 83 & 217 \\
1 & PARITY & VBAC (\%) & FAILED VBAC & TOTAL \\
2 & 2 & $53(39.5)$ & $58(69.9)$ & 111 \\
3 & 3 & $45(33.6)$ & $15(18.1)$ & 60 \\
4 & 4 & $24(17.9)$ & $5(6.0)$ & 29 \\
\hline
\end{tabular}

(b)

\begin{tabular}{ccccc}
\hline S/N & INTERDELIVERY INTERVAL & VBAC $(\%)$ & FAILED VBAC & TOTAL \\
\hline 1 & $<2$ years & $39(29.1)$ & $22(26.5)$ & 61 \\
2 & $2-3$ years & $34(25.4)$ & $48(57.8)$ & 82 \\
3 & $>3$ years & $61(45.5)$ & $13(15.7)$ & 74 \\
S/N & BOOKING STATUS & VBAC $(\%)$ & FAILED VBAC & TOTAL \\
1 & Booked & $105(78.4)$ & $55(66.3)$ & 160 \\
2 & Unbooked & $29(21.6)$ & $28(33.7)$ & 57 \\
S/N & VAGINAL DELIVERY & VBAC (\%) & FAILED VBAC & TOTAL \\
1 & Previous vaginal delivery & $68(50.7)$ & $23(27.7)$ & 91 \\
2 & No previous vaginal delivery & $66(49.3)$ & $60(72.3)$ & 126 \\
\hline
\end{tabular}


Table 2. Indication for previous $\mathrm{C} / \mathrm{S}$.

\begin{tabular}{ccccc}
\hline S/N & INDICATION FOR PREVIOUS C/S & VBAC (\%) & $\begin{array}{c}\text { FAILED } \\
\text { VBAC } \%\end{array}$ & TOTAL \\
\hline 1 & Malpresentation & $40(29.8)$ & $28(33.8)$ & 68 \\
2 & Cephalopelvic disproportion & $19(14.2)$ & $19(23.0)$ & 38 \\
3 & Antepartum haemorrhage & $26(19.4)$ & $2(2.4)$ & 28 \\
4 & Foetal distress & $13(9.7)$ & $5(6.0)$ & 18 \\
5 & Prolonged labour & $10(7.5)$ & $5(6.0)$ & 15 \\
6 & Hypertensive disorders of pregnancy & $13(9.7)$ & $2(2.4)$ & 15 \\
7 & Obstructed labour & $3(2.2)$ & $10(12.0)$ & 13 \\
8 & Poor progress of labour & 0 & $2(2.4)$ & 2 \\
9 & Others & $10(7.5)$ & $10(12.0)$ & 20 \\
& & 134 & $\mathbf{8 3}$ & 217 \\
\hline
\end{tabular}

cephalopelvic disproportion (45.8\%), poor progress (19.3\%) and hypertensive disorders of pregnancy $(8.4 \%)$ respectively (Table 3 ). The birth weight of the babies ranged from $1.95 \mathrm{~kg}$ to $4.1 \mathrm{~kg}$.

As highlighted in Table 4, there were 6 cases of postpartum haemorrhage in the group that had successful vaginal birth after Caesarean section while there was no case of postpartum haemorrhage in the group that had repeat Caesarean section. Under the group that had successful vaginal birth after Caesarean section, there was also a case of uterine rupture (seen in one of the 5 successful VBAC patients whose labour was augmented) and retained placenta compared to the repeat Caesarean section group that did not have these complications. APGAR Scores of less than 7 in the $1^{\text {st }}$ and $5^{\text {th }}$ minutes respectively are comparable in both groups. Also, birth weights of 3.1 to $3.5 \mathrm{Kg}$ are found majorly in both groups.

\section{Discussion}

Since 1985, the international healthcare community has considered the ideal Caesarean section rate to be from $10 \%-15 \%$ [21]. A Caesarean section rate of $29.8 \%$ found in this study is greater than this figure. It is also higher than the 27.6\% found in Enugu [22]. This was probably due to the fact that quite a number of the patients were referrals from peripheral hospitals who might have received suboptimal care prior to their being referred. The success rate of vaginal birth after Caesarean section quoted as $61.8 \%$ found in this study is higher than the 52.5\% reported in Bauchi and 50\% in Enugu [23] [24]. It is comparable to the 59.37\% reported from New Delhi, India [25]. However, it is lower than a success rate of $67.4 \%$ reported from Ogbomoso and $69.1 \%$ reported from Lagos [26] [27]. It is also lower than the $72 \%-76 \%$ quoted for developed countries [28]. This high success rate can be attributed to good patient selection as majority were booked and they benefited from antenatal care. The indications for the 
Table 3. Indication for terminating TOLAC.

\begin{tabular}{ccc}
\hline S/N & INDICATION FOR TERMINATION OF TOLAC & PERCENTAGE \\
\hline 1 & Cephalopelvic Disproportion & $45.8 \%(38)$ \\
2 & Poor Progress of Labour & $19.3 \%(16)$ \\
3 & Hypertensive Disorders of Pregnancy & $8.4 \%(7)$ \\
4 & Obstructed Labour & $7.2 \%(6)$ \\
5 & Malpresentation & $3.6 \%(3)$ \\
6 & Foetal Distress & $3.6 \%(3)$ \\
7 & Others & $12.0 \%(10)$ \\
8 & Total & $100 \%(83)$ \\
\hline
\end{tabular}

termination of the attempt at vaginal birth after Caesarean section in order of prominence were cephalopelvic disproportion $(45.8 \%)$, poor progress $(19.3 \%)$ and hypertensive disorders of pregnancy (8.4\%) (see Table 3 ). This was comparable to findings from Lagos [26].

The age distribution of the patients attempting vaginal birth after Caesarean section is as shown in Table 1. It is similar to the age distribution of the patients in the study at Nnewi [9]. The birth weight is as shown in Table 4. The findings were in contrast to the study in Bauchi and that by Oboro [23] [26] (Table 4).

The use of oxytocin for augmentation of labour in women with a previous Caesarean section has remained controversial because of speculation that there might be an increased risk of uterine dehiscence [29]. Eleven of the patients that attempted vaginal birth after Caesarean section had augmentation of labour and 5 of them had successful vaginal birth after Caesarean section (45.5\%) while 6 (54.5\%) had repeat Caesarean section. One of the 5 successful cases whose labour was augmented had uterine rupture that was noticed shortly in the postpartum period. She immediately had exploratory laparotomy and repair of linear uterine ruptured along the previous lower segment uterine scar. Bilateral tubal ligation was not carried out though the patient and her relatives were thoroughly counselled on the risk of uterine rupture in subsequent pregnancies and the need to have her pregnancy monitored in a tertiary health facility. In a study in Lagos, none of the 8 patients that were augmented had uterine rupture [27]. This study confirmed that short hospital stay was a recognized benefit of attempt at vaginal birth after Caesarean section [16] [19].

In this study, patients with previous vaginal delivery, age between 25 and 29 years and interdelivery interval of greater than or equal to two years were noticed to be more successful at achieving vaginal birth after Caesarean section than those that were not (Table 1). This contrasts with the report from Nnewi in which there was no significant association between the outcome of vaginal birth after Caesarean section and history of vaginal birth. However, it was in agreement with previous observation by some other investigators [12] [13] [23].

Vaginal birth after Caesarean section remains an important tool for the reduction 
Table 4. Maternal and fetal outcome.

\begin{tabular}{|c|c|c|c|c|}
\hline S/N & Complication & VBAC No & & \\
\hline 1 & Postpartum Haemorrhage & 6 & & \\
\hline 2 & Uterine Rupture & 1 & & \\
\hline \multirow[t]{4}{*}{3} & Retained Placenta & 1 & & \\
\hline & APGAR SCORE LESS THAN 7 & VBAC (\%) & FAILED VBAC (\%) & \\
\hline & $1 \mathrm{~min}$ & $9(6.7)$ & $6(7.2)$ & \\
\hline & $5 \mathrm{~min}$ & $5(3.7)$ & $5(6.0)$ & \\
\hline $\mathrm{S} / \mathrm{N}$ & Birth weight & VBAC (\%) & FAILED VBAC (\%) & TOTAL \\
\hline 1 & $<2 \mathrm{~kg}$ & $3(2.2)$ & 0 & 3 \\
\hline 2 & $2.1-2.5 \mathrm{~kg}$ & $8(5.8)$ & $5(6.0)$ & 13 \\
\hline 3 & $2.6-3 \mathrm{~kg}$ & $42(31.2)$ & $25(30.1)$ & 67 \\
\hline 4 & $3.1-3.5 \mathrm{~kg}$ & $55(41.3)$ & $40(48.2)$ & 95 \\
\hline 5 & $3.6-4 \mathrm{~kg}$ & $23(17.4)$ & $11(13.3)$ & 34 \\
\hline 6 & $>4 \mathrm{~kg}$ & $3(2.2)$ & $2(2.4)$ & 5 \\
\hline $\mathrm{S} / \mathrm{N}$ & Duration of Admission & VBAC (\%) & FAILED VBAC & TOTAL \\
\hline 1 & $<4$ days & $129(96.3)$ & 0 & 129 \\
\hline 2 & $>4$ days & $5(3.7)$ & $83(100)$ & 88 \\
\hline
\end{tabular}

of Caesarean section rate [2]. However, patients must meet some criteria including non recurrent indication for previous Caesarean section, low transverse uterine incision as well as the labour taking place in an adequately staffed and well equipped facility with competent personnel and operative capability round the clock [19]. This is imperative in order to avoid the untoward effect of attempt at vaginal birth after Caesarean section such as postpartum haemorrhage and uterine rupture. When they do occur, proper monitoring of labour is recommended to ensure early detection and institution of interventions to limit morbidity and prevent mortality [19].

\section{Limitation}

Missing data that could not be accountable for is a drawback to this study.

\section{Conflicts of Interest}

The authors declare no conflicts of interest regarding the publication of this paper.

\section{References}

[1] McEwan, A. (2011) Labour. In: Baker, P. and Kenny, L., Eds., Obstetrics by Ten Teachers, 19th Edition, Bookpower, London, 185-223. https://doi.org/10.1201/b13484-15

[2] (2014) Prior Cesarean Delivery. In: Cunningham, F.G., Leveno, K.J. and Bloom, 
S.L., et al., Eds., Williams Obstetrics, 24th Edition, McGraw-Hill Companies, New York, 609-621.

[3] Cragin, E. (1916) Conservatism in Obstetrics. New York Medical Journal, 104, 1.

[4] Flamm, B.L. (1997) Once a Cesarean, Always a Controversy. Obstetrics \& Gynecology, 90, 312. https://doi.org/10.1016/S0029-7844(97)00263-9

[5] Calder, A.A. and Arulkumaran, S. (Eds.) (2007) Vaginal Birth after Caesarean Section. In: Basket, T.F., Ed., Munro Kerr's Operative Obstetrics, 11th Edition, Saunders, Philadelphia, 167-174.

[6] Martin, J.A., Hamilton, B.E., Ventura, S.J., et al. (2012) Births: Final Data for 2010. National Vital Statistics Reports, 61, 1.

[7] Sachs, B.P., Koblin, C., Castro, M.A., et al. (1999) The Risk of Lowering the Cesarean Delivery Rate. The New England Journal of Medicine, 340, 5. https://doi.org/10.1056/NEJM199901073400112

[8] Ebeigbe, P.N. and Ilesanmi, A. (2004) Caesarean Delivery. In: Okpere, E., Ed., Clinical Obstetrics, Uniben Press, Benin, 337-343.

[9] Ikechebelu, J.I., Mbamara, S.U. and Afuba, A.N. (2010) Vaginal Birth after Caesarean Section: A Review of the Practice in Nnewi, Southeast Nigeria. The Journal of Medical Sciences, 1, 301-313.

[10] Ola, E.R., Imosemi, O.D. and Abudu, O.O. (2010) Vaginal Birth after 1 Previous Caesarean Section-Evaluation of Predictive Factors. African Journal of Medicine and Medical Sciences, 30, 61-66.

[11] Aisien, A.O. and Oronsaye, A.U. (2004) Vaginal Birth after One Caesarean Section in a Tertiary Institution in Nigeria. Journal of Obstetrics and Gynaecology, 24, 886-890. https://doi.org/10.1080/01443610400018742

[12] Grinstead, J. and Grobman, W.A. (2004) Induction of Labor after One Prior Cesarean: Predictors of Vaginal Delivery. Obstetrics \& Gynecology, 103, 534. https://doi.org/10.1097/01.AOG.0000115508.75370.23

[13] Mercer, B.M., Gilbert, S., Landon, M.B., et al. (2008) Labor Outcomes with Increasing Number of Prior Vaginal Births after Cesarean Delivery. Obstetrics \& Gynecology, 111, 285. https://doi.org/10.1097/AOG.0b013e31816102b9

[14] Shipp, T.D., Zelop, C.M., Repke, J.T., et al. (2001) Interdelivery Interval and Risk of Symptomatic Uterine Rupture. Obstetrics \& Gynecology, 97, 175.

[15] Elkousy, M.A., Sammel, M., Stevens, E., et al. (2003) The Effect of Birth Weight on Vaginal Birth after Cesarean Delivery Success Rates. American Journal of Obstetrics \& Gynecology, 188, 824. https://doi.org/10.1067/mob.2003.186

[16] Omigbodun, A.O. (2002) Vaginal Birth after Caesarean Section. In: Kwawukume, E.Y. and Emuveyan, E.E., Eds., Comprehensive Obstetrics in the Tropics, Asante \& Hittscher Press, Accra, Vol. 16, 122-128.

[17] Esposito, M.A., Menihan, C.A. and Mallee, M.P. (2000) Association of Interpregnancy Interval with Uterine Scar Failure in Labor; A Case Control Study. American Journal of Obstetrics \& Gynecology, 183, 1180-1183. https://doi.org/10.1067/mob.2000.109046

[18] Hibbard, J.U., Gilbert, S., Landon, M.B., et al. (2006) Trial of Labor or Repeat Cesarean Delivery in Women with Morbid Obesity and Previous Cesarean Delivery. Obstetrics \& Gynecology, 108, 125-133. https://doi.org/10.1097/01.AOG.0000223871.69852.31

[19] Incerpi, M.H. (2007) Operative Delivery. In: Decherney, A.H., Nathan, L., Goodwin, T.M., et al., Eds., Current Obstetric and Gynaecologic Diagnosis and Treat- 
ment, 10th Edition, McGraw-Hill Companies, New York, Vol. 30, 461-476.

[20] Abderrahim, A., Taofiq, C., Kamal, E.L., et al. (2001) Induction of Labor with Intravaginal Misoprostol after Caesarean Delivery. African Journal of Reproductive Health, 5, 139-141.

[21] World Health Organization (1985) Appropriate Technology for Birth. The Lancet, 2, 436-437.

[22] Ugwu, E.O., Obioha, K.C., Okezie, O.A., et al. (2011) A Five-Year Survey of Caesarean Delivery at a Nigerian Tertiary Hospital. Annals of Medical and Health Science Research, 1, 77-83.

[23] Aliyu, L.D., Yakasai, I.A., Ezugwu, O.P., et al. (2013) Vaginal Birth after Caesarean Section (VBAC): A Two Year Comparative Review of Outcome at Abubakar Tafawa Balewa University Teaching Hospital Bauchi Nigeria. Asian Journal of Natural and Applied Sciences, 189-194.

[24] George, O.U., Chukwuemeka, A.I., Hyacinth, E.O., et al. (2014) Maternal and Perinatal Outcomes of Delivery after Caesarean Section in Enugu, Southeast Nigeria: A Prospective Observational Study. International Journal of Women's Health, 6, 301-305.

[25] Gupta, P., Jahan, I. and Jograjiya, G.R. (2014) Is Vaginal Delivery Safe after Previous Lower Segment Caesarean Section in Developing Country? Nigerian Medical Journal, 55, 260-265. https://doi.org/10.4103/0300-1652.132067

[26] Oboro, V., Adewunmi, A., Ande, A., et al. (2010) Morbidity Associated with Failed Vaginal Birth after Caesarean Section. Acta Obstetricia et Gynecologica Scandinavica, 89, 1229-1232. https://doi.org/10.3109/00016349.2010.499448

[27] Ezechi, O.C., Kalu, B.K., Njokanma, F.O., et al. (2005) Trial of Labour after a Previous Caesarean Section Delivery: A Private Hospital Experience. Annals of African Medicine, 4, 113-117.

[28] Royal College of Obstetricians and Gynaecologists (2007) Birth after Previous Caesarean Birth, Green Top Guidelines, 45.

[29] Shimonovitz, S., Botosneano, A. and Hochner-Celnikier, D. (2000) Successful First Vaginal Birth after Caesarean Section: A Predictor of Reduced Risk for Uterine Rupture in Subsequent Deliveries. The Israel Medical Association Journal, 2, 526-528. 